\title{
Mondor's Disease after Operation for Axillary Osmidrosis: A Case Report
}

\author{
Jun Yong Lee, Young Il Ko, \\ Min Cheol Lee, Ho Kwon, \\ Sung-No Jung
}

Department of Plastic and Reconstructive Surgery, College of Medicine, The Catholic University of Korea, Uijeongbu, Korea

No potential conflict of interest relevant to this article was reported.

\begin{abstract}
Mondor's disease is a benign, self-limited process with spontaneous resolution, which is frequently caused by breast surgery, such as axillary lymph node dissection. We present a case of Mondor's disease that occurred after an axillary osmidrosis operation, which is a less invasive procedure; Mondor's disease may be considered as a possible postoperative complication following an axillary osmidrosis surgery.
\end{abstract}

Keywords Mondor's disease, Axillary osmidrosis, Superficial thrombophlebitis

\section{INTRODUCTION}

Mondor's disease was first described in 1939 by Henri Mondor. The disease was initially described as a superficial vein thrombosis, involving either the lateral thoracic, the thoracoepigastric or the superior epigastric vein [1]. To date, many cases of such superficial thrombophebitis arising from various parts of the body have been reported, with the breast and the chest wall being the most commonly involved area [2]. We report a case of Mondor's disease, a rare complication that occurred after treatment of axillary osmidrosis.

\section{CASE}

A 36-year-old female underwent a radiofrequency ablation therapy for axillary osmidrosis at a local clinic. Two weeks after the procedure, she visited our outpatient department presenting with pain in her right axillary area, and restricted range of motion of her

Received: Sep 20, 2013 Revised: Oct 10, 2013 Accepted: Oct 18, 2013 Correspondence: Sung-No Jung Department of Plastic and Reconstructive Surgery, Uijeongbu St. Mary's Hospital, College of Medicine, The Catholic University of Korea, 271 Cheonbo-ro, Uijeongbu 480-717, Korea.

E-mail: jsn7190@catholic.ac.kr

http://submit.e-aaps.org/

Copyright $\odot 2013$ The Korean Society for Aesthetic Plastic Surgery.

This is an Open Access article distributed under the terms of the Creative Commons Attribution Non-Commercial License (http://creativecommons.org/licenses/by-nc/3.0/) which permits unrestricted non-commercial use, distribution, and reproduction in any medium, provided the original work is properly cited right upper arm along with disruption of the wound site. There was a tender, cord-like structure in the subcutaneous layer of the medial aspect of her right upper arm (Fig. 1), and the range of motion of the right shoulder during abduction was limited to less than 100 degrees (Fig. 2). We diagnosed her with Mondor's disease and managed conservatively with antibiotics and analgesics. The patient's pain on her axillary area started to resolve one week after the treatment. Three months later, her symptoms resolved completely without any sequale. The tender, cord-like structure on the medial side of the right upper arm had resolved without any noticeable scar, and the range of motion of the patient's right shoulder was fully recovered as well.

\section{DISCUSSION}

Mondor's disease presents with a subcutaneous, tender, cord-like induration without any inflammatory signs, with a free, mobile overlying skin. The lesion may be asymptomatic but some patients experience pain on palpation or during stretching movements [3]. It is a superficial thrombophlebitis that affects the subcutaneous veins, and involves various parts of the body including the mammary area, axilla, antecubital fossa, posterior cervical region, penis and groin [2].

The diagnosis is based on clinical findings. The differential diagnosis of Mondor's disease are vasculitis such as subacute angeitis, cutaneous polyarteritis nodosa, and angeitis due to drugs; however, these diseases are accompanied by severe pain and involve arteries rather than veins [3]. Ultrasonography may sometimes be helpful, which reveals a distended, flowless vein with a beaded appearance, 


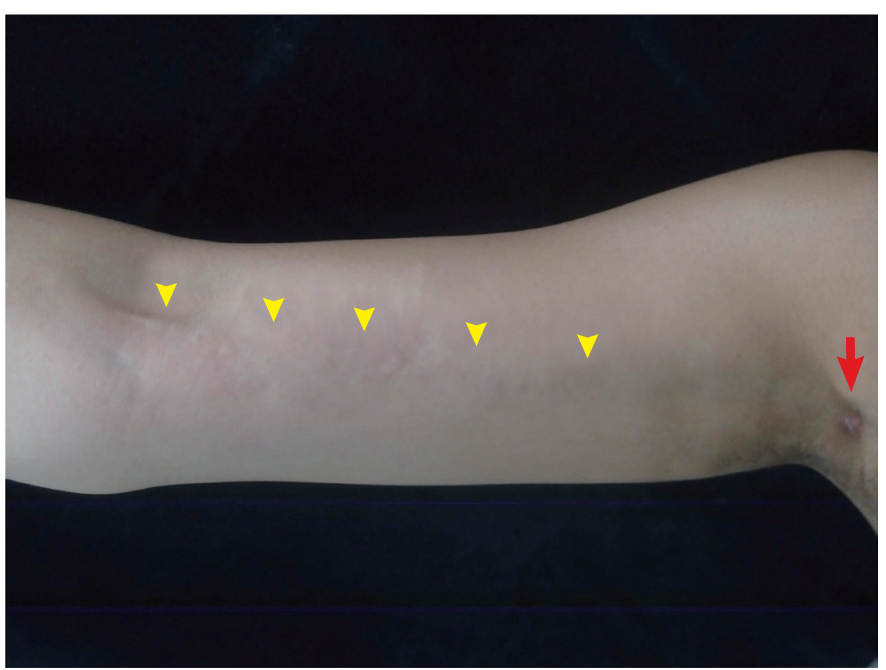

Fig. 1. Tender cord-like structure in the subcutaneous layer of the medial side of the patient's right upper arm (head of yellow arrow) and disrupted wound (red arrow).

and can confirm the absence of any possible underlying mass compressing the veins [4]. Coagulation tests could be performed in order to exclude hypercoagulability conditions. Enlargement of lymphatics due to lymphangiectasia or lymphangioma and metastatic carcinoma of the skin should also be considered as its possible differential diagnosis [3].

In 2001, Moskovitz et al described the axillary web syndrome as an axillary variant of Mondor's disease, which is characterized by axillary pain that runs down the medial arm, limited range of motion of the shoulder, and the presence of cords of subcutaneous tissue that extend from the axilla to the medial arm [5]. The causes of the disease are well known, which include previous trauma or breast surgery such as axillary lymph node dissection or accessory breast resection [6,7]; however, we experienced a case of Mondor's disease after the operation of axillary osmidrosis, which is a relatively less invasive procedure than those mentioned above. Of note, the patient had a history of undergoing radiofrequency ablation to treat her axillary osmidrosis in the case presented above; given that this treatment method accompanies unintended thermal damage to the surrounding tissue, such mechanism may have participated in inducing the unusual complication, though no similar reports have been made to date.

Mondor's disease is a benign, self-limited process with spontaneous resolution. The pain usually decreases within 10 days, but an asymptomatic or tender cord can remain for weeks or months. Treatment is conservative, which includes local application of heat, resting the affected arm, breast support and conventional analgesics [8]; should this be insufficient, or in case of recurrence, a thrombectomy or superficial vein resection may be necessary [9].

Although uncommon and self-limiting in its nature, Mondor's disease can be considered as a possible postoperative complication

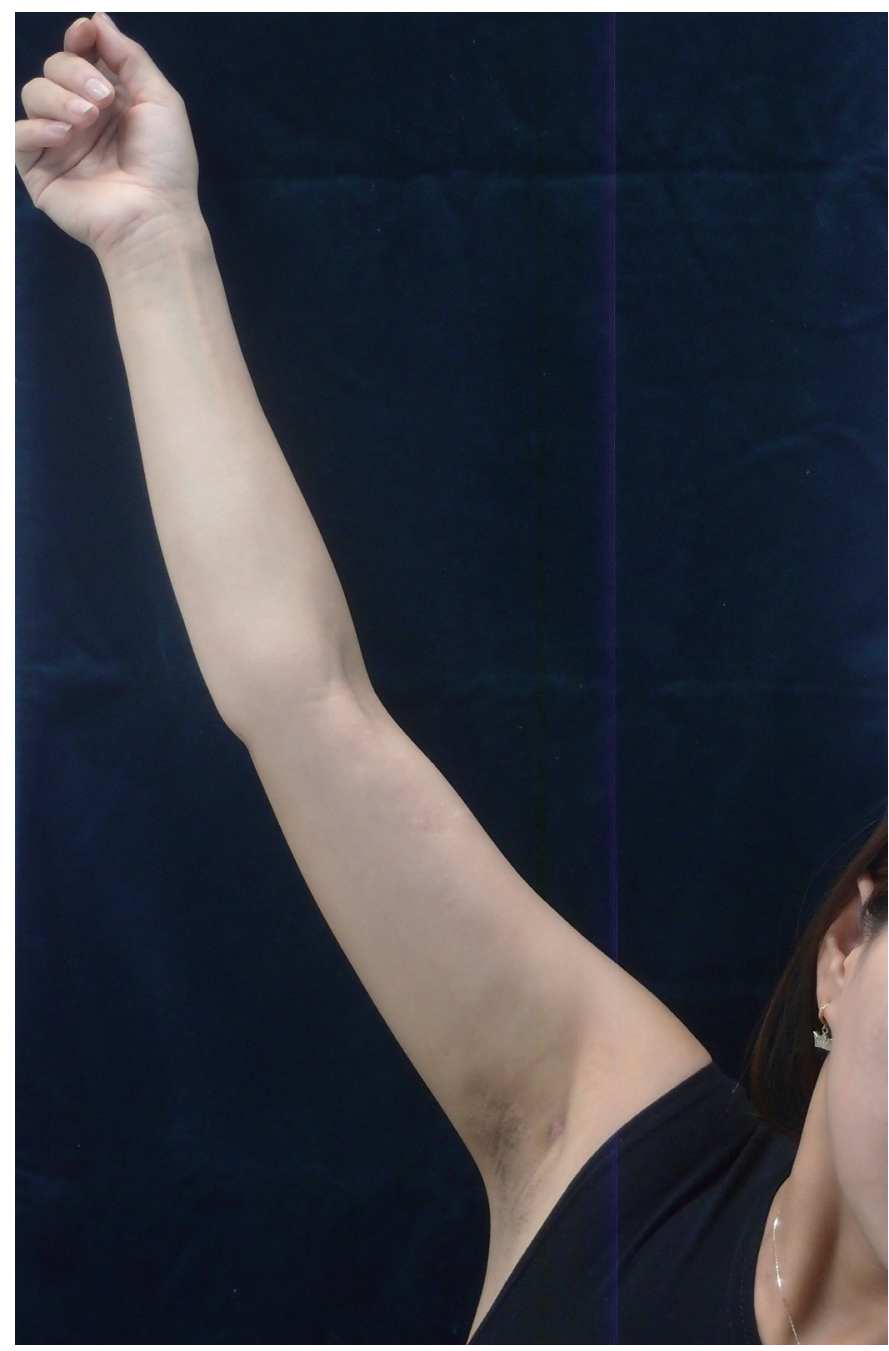

Fig. 2. Limited range of motion of the right shoulder on abduction. The patient involuntarily bent her back when she was made to outstretch and raise her arm.

that occurs after an axillary osmidrosis surgery. Sufficient explanation regarding its possibility should be provided to the patient before surgery, and in case of its occurrence, reassurance should be made to the patient about the self-limiting nature of this disease.

\section{REFERENCES}

1. Mondor H. Tronculité sous cutanée subaigue de la paroi thoracique antéro latérale. Mem Acad Chir 1939;65:258-71.

2. Roscher AA, Weinstein E. The clinic-pathological spectrum of Mondor's disease: an important surgical entity. Int Surg 1980; 65:325-9.

3. Alvarez-Garrido H, Garrido-Rios AA, Sanz-Munoz C, et al. Mondor's disease. Clin Exp Dermatol 2009;34:753-6.

4. Yanik B, Conkbayir I, Oner O, et al. Imaging findings in Mondor's disease. J Clin Ultrasound 2003;31:103-7. 
5. Moskovitz AH, Anderson BO, Yeung RS, et al. Axillary web syndrome after axillary dissection. Am J Surg 2001;181:434-9.

6. Salemis NS, Merkouris S, Kimpouri K. Mondor's disease of the breast. A retrospective review. Breast Dis 2011;33:103-7.

7. Craythome E, Benton E, Macfarlane S. Axillary web syndrome or cording, a variant of mondor disease, following axillary sur- gery. Arch Dermatol 2009;145:1199-200.

8. Mayor M, Burón I, de Mora JC, et al. Mondor's disease. Int J Dermatol 2000;39:922-5.

9. Onder M, Canpolat B, Aksakal B, et al. Case of Mondor's disease of the abdomen (body-building induced). Int J Dermatol 2005; 44:345-6. 